\title{
Effectiveness of Top-Down Construction Method in Malaysia
}

\author{
Jing-Ying Wong, Chun-Chieh Yip, Kevin Luwemba Mugumya, Bing-Hong Tan, Mohammed \\ Parvez Anwar
}

\begin{abstract}
Top-down construction (TDC) method provides a significant saving in the construction time. The building sequence starts with the construction of retaining wall and the underground load bearing elements which carry the future superstructure. This research aims to evaluate the strength and weakness of TDC approach compared to the conventional bottom-up method in Malaysia through different aspects and improvements are proposed at the end of the study. The questionnaire survey is conducted with the targeted parties who are working in the construction industry. 102 respondents have been responded to the survey. Then, a TDC project in the Kuala Lumpur City Center (KLCC) is selected as the case study in this research. Project information and interview sessions are conducted with the person in charge of the project to obtain an in-depth understanding of the constraints of this method. Survey results show that TDC method is safer for deep underground construction and lesser effects to the surrounding buildings in Malaysia. However, training is required for the contractors to increase the project efficiency. Conclusively, some improvements should be adopted when top-down method inevitably becomes a tendency in the construction industry in Malaysia.
\end{abstract}

Index Terms- Top-down construction, effectiveness, feasibility, improvement.

\section{INTRODUCTION}

Among numerical countries in Southeast Asia, Malaysia is one of the rapid developing countries which undergoes a fast economic growth since the 1970s. In the first quarter of 2019, the value of the construction work done reached RM 37.4 billion [1]. This result indicates that construction industry plays an important role in the economic development Malaysia.

Development of the new projects is affected by several factors, e.g. availability of building's space. In Malaysia, the urban areas are occupied by the high-rise buildings such as Kuala Lumpur City Centre (KLCC) area. Office towers, apartments, hotels and shopping complexes can be seen everywhere and within $700 \mathrm{~m}$ from the local landmark, Petronas Twin Towers. Any substructure construction projects in this area are more complicated than other places, hence studies on the foundation formations of other existing

Revised Manuscript Received on April 12, 2019.

Jing-Ying Wong,Department of Civil Engineering, University of Nottingham Malaysia Campus, 43500 Semenyih, Selangor, Malaysia. (JingYing.Wong@nottingham.edu.my)

Chun-Chieh Yip,Department of Civil Engineering, UniversitiTunku Abdul Rahman Sungai Long Campus, 43000 Kajang, Selangor, Malaysia. (yipcc@utar.edu.my)

Kevin LuwembaMugumya,Department of Civil Engineering, University of Nottingham Malaysia Campus, 43500 Semenyih, Selangor, Malaysia. (keey4kly@nottingham.edu.my)

Bing-Hong TanDepartment of Civil Engineering, University of Nottingham Malaysia Campus, 43500 Semenyih, Selangor, Malaysia. (keey3tbg@nottingham.edu.my)

Mohammed Parvez Anwar, Department of Civil Engineering, University of Nottingham Malaysia Campus, 43500 Semenyih, Selangor, Malaysia. (Anwar.Parvez@nottingham.edu.my) buildings nearby become particularly important. The requirement of land increases progressively over the years but only limited space is allowed for the construction of purpose-built office buildings and shopping malls. When the demand is greater than the supply, a rise in the land price in the market will occur particularly in the major cities. Hence, the landowners will seek for a way to fully utilise the space and shorten the project duration to increase their profits.

Due to the restriction of the building height and other constraints on the ground surface, people start to explore the possibility of using underground space and development of the basements for car parking or public transportation stations. It is inevitable that the underground construction is commonly more expensive than above ground construction. However, it is still a valuable investment compared with the land cost and future operating profit. Most of the construction projects are planned on fast track basis, any approach which can increase the project productivity is preferred.

Conventional bottom-up and cut-cover methods become impractical in the crowded urban area especially in KLCC, that needs a significant amount of extra construction costs is added for the foundation consolidation and neighbouring buildings protection. From the last century, bottom-up construction has been widely used as an excavation method for underground construction [2]. Bottom-up construction method as the name implied, the construction starts sequentially from the bottom level of substructure to the highest level of the superstructure. The excavation begins in the enclosed area until the desired depth after completion of the pile foundation and retaining wall installation, temporary strutting or bracing system is required during the excavation process to support the basement walls from movement. Temporary support system with large slenderness ratio is used to carry the load induced by the surrounding soil removal, the strut is compressed by the wall movement and it is adjustable by the load measurement of the strut [3].

Hence, TDC method becomes the only feasible way in this particular area. It is an innovative construction approach which is initially introduced in major European city centres over the world to achieve higher utilisation of underground space with a shorter construction duration during the 20th century [4], [5]. Substructure and superstructure construction can be executed simultaneously by using the TDC construction method [6].

In the beginning, there was no advanced technology to accelerate the construction time when using TDC method. Temporary steel beam columns were used to provide 
limited capacities for the floor slabs erection due to their flexibility, they were then cast in concrete before the construction of superstructure level. However, contractors did not dare to take the risk of constructing two to three floors of the superstructure before completion of substructure because of the limited carrying capacity. Owing to the requirement of short construction period, temporary steel beam columns are replaced by the bored columns with high stiffness and carrying capacity soon. This replacement brings the TDC technique to a new milestone and spreads all over the world [7].

In the TDC method, basement floor slabs and beams act as important elements to prop the diaphragm walls [8]. Two major types of permanent load-bearing elements installation techniques are used due to the different embedded depth, column size and bored piles size, which are pre-concreting installation method and post-concreting installation or plunging method [9].However, this method started to be adopted in Malaysia recently. Hence, several projects only in Kuala Lumpur utilise this method for the substructure construction and the effectiveness of this construction method is investigated. It is undeniable that the project time, cost, quality and performance are the key criteria for a successful construction project [10]. A common phenomenon in the construction of developing country is overruns of the project time, it raises a major problem in the project development in Malaysia [11].

Additional charges and professional fees and lesser profits are caused by the late occupancy of the buildings to the clients or stakeholders [12]. However, Wright [13] claimed that the list should be reduced and taking into the consideration of clients view which only two parameters are vital, budget and time. Completing projects within the time provided is an indicator of the efficient construction industry [14]. In this research, only these two parameters are adopted to measure the effectiveness of the TDC method in Malaysia.

\section{METHODOLOGY}

Questionnaire survey and interview session on case study was conducted. Semi-structured and non-structured questions were prepared to obtain qualitative information. An ongoing project in the Kuala Lumpur City Centre (KLCC) area was selected in this research to study the techniques and issues faced using TDC methods. Due to the confidential agreement between the researcher and the company, the detailed information of the company and studied project will not be disclosed in this paper.

\section{RESULTS AND DISCUSSIONS}

\section{A. Questionnaire Survey}

102 respondents from the industry players in Malaysia have participated in this survey. There are 28 from contractor firm (27\%), 25 from structural consultancy (25\%), 28 from geotechnical consultancy $(27 \%)$ and 21 from others $(21 \%)$. In 21 responses from the other company natures, there are $43 \%$ from the developer, $29 \%$ from the academic institution, $14 \%$ from the water consultancy, $10 \%$ from the architectural firm and remaining 5\% from the project management consultancy.
The number of respondents from the four main categories (contractor, structural consultancy, geotechnical consultancy and others) are used to check the bias of the data collected using Cronbach's Alpha Analysis. Chelsea [15] stated that, "Cronbach's alpha is measured by correlating the score for each scale item with the total score for each observation (usually test participants or questionnaire survey respondents) and compares it with the variance for all individual item scores". An average Cronbach's Alpha value of 0.973 is obtained and the interitem correlation is in a range of 0.828 to 1.000 which are on an excellent reliability level of non-bias [16].

\section{B. Experience and Understanding of TDC Method}

Based on the data collected, the respondents vary from different level of experience in the construction industry. Most of the respondents are from the group of 1 to 5 years working experience which contribute to $67 \%$ of the total responses. Total of 17 respondents from the group of 11 to 15 years working experience and above 15 years working experience are $15 \%$ and $10 \%$ respectively. Only $8 \%$ of the respondents have 6 to 10 years working experience. Although majority of the respondents have less than 5 years working experience, their evaluation on the effectiveness of the TDC method is still considerable and represented as this approach only being adopted in Malaysia recently.

From the investigation, $85.29 \%$ of the 102 respondents has explored to the TDC method while the remaining $14.71 \%$ never learn about this method. In the discussion of the following parts, only the 87 respondents (from the $85.29 \%$ ) are used to study the effectiveness of the TDC to increase the result accuracy.

In order to get the relationship, cross tabulation method is used to integrate the respondents' working experience with their understanding as presented in Fig. 1. Apart from 6 to 10 years working experience, other categories have more than $80 \%$ respondents understand this method. From the short interview with some of the respondents in the category of 1 to 5 years, they stated that TDC method has been covered during their university time. On the other hand, some of the respondents from the group of 10 years above working experience have been involved in the TDC project in other countries or attended related training there.

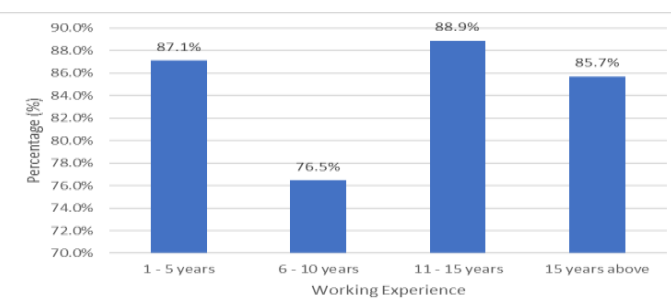

Figure 1. Working Experience and Understanding of TDC

\section{Involvement of TDC Project in Malaysia}

Even $85.29 \%$ of the respondents know about TDC method, but there are only 45 out of 102 responses $(44.12 \%)$ involved in the top-down project. From Fig. 2, geotechnical 
consultancies and contractor firms have the higher involvement in the TDC project which are $60.71 \%$ and $57.14 \%$ respectively. Structural consultancies hold the next optimistic percentage of $32 \%$ respondents involved in the TDC before while it is only $19.05 \%$ of the respondents from others.

It is believed that the methods for designing soil restraining system in TDC method such as diaphragm wall and raft foundation are similar to the conventional structures. Hence, it can be done by the local geotechnical consultancies. As the project sites are in Malaysia, it is preferable to engage local contractor firms in handling the projects with the supervision of experts in this method.

Hence, it causes the contractor firms to have a higher involvement rate. Instead of temporary strutting, slab acts as permanent supports to the movement of the diaphragm wall during the construction stage and particular design is needed for the slab reinforcement with the consideration of lateral force resistance. Therefore, design work becomes extremely complicated and lesser involvement of local inexperienced structural consultancies. TDC is particularly useful for the high-rise building or underground metro station so it made the involvement rate is lowest in the categories classified under "others".

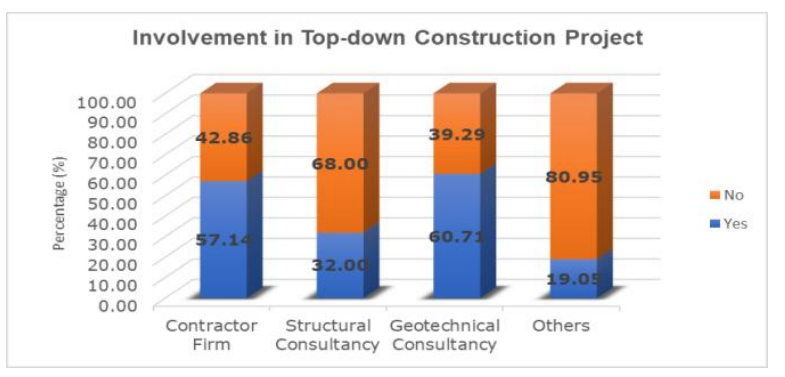

\section{Figure 2. Respondents' Involvement in TDC Project}

\section{Feasibility and Safety of TDC Method}

Total of $59.77 \%$ respondents agreed that TDC method is a more feasible method than the conventional bottom-up method if the site situation is constrained. The same number of respondents agreed that TDC method generates lesser safety problems than the conventional bottom-up method. It means that 35 respondents, equivalent to $40.23 \%$, argued that there are more safety problems by adopting TDC method.

Spearman's analysis is used to determine the correlation between feasibility and safety of TDC method from the opinion of the industry players. As illustrated in Table I, a Spearman's rho value of 0.761 is obtained from the calculation which represents a good relationship between the items evaluated. It can be assumed that $76.1 \%$ of the respondents claimed that TDC method is feasible because it produces lesser safety problems than the bottom-up construction method.

Due to the more complicated work sequence of the TDC method, lifting is a common activity on site for the horizontal and vertical transfer of machinery and materials. Hence, it has the possibility to increase the risk of the logistics. According to Choo [17], most of the activities were carried out under a confined space in the TDC project. It increases the challenges of machinery movement and produces a polluted working environment underneath. One of the proposed solutions is to install the ventilation fans to refresh the air in the bottom level and thus provide a safer working environment.

Table I Spearman's Correlation Analysis of Feasibility and Safety Concern

\begin{tabular}{|c|c|c|c|c|}
\hline \multicolumn{5}{|c|}{ Correlations } \\
\hline & & & Feasibility & Safety \\
\hline \multirow{6}{*}{ Spearman's rho } & \multirow{3}{*}{ Feasibility } & Correlation Coefficient & 1.00 & $0.761^{* *}$ \\
\hline & & Sig. (2-tailed) & & 0.00 \\
\hline & & $\mathrm{N}$ & 87.00 & 87.00 \\
\hline & \multirow[t]{3}{*}{ Safety } & Correlation Coefficient & $0.761^{\text {** }}$ & 1.00 \\
\hline & & Sig. (2-tailed) & 0.00 & \\
\hline & & $\mathrm{N}$ & 87.00 & 87.00 \\
\hline
\end{tabular}

\section{E. Possible Problems in Adopting TDC Method}

The possible problems happened in the TDC are the crucial parts to be managed and it will affect the mind of the decision maker to adopt this method. This section seeks for the opinion from the respondents of the relevant problems found to occur during the construction stage.

As the result tabulated in Table II, requirement of the professional contractors is the most possible problem faced in TDC method project with a Relative Importance Index (R.I.I) value of 0.830 . Earlier participation of the contractors can significantly reduce the work mistake and affect the entire progress planning of the project. Hence, it is important to hire professional contractors to coordinate with the consultants during the design stage.
Moreover, the requirement of specific machinery, higher construction cost and need of complicated design have a similar range of possibility which are from R.I.I value of 0.755 to 0.791 . Clamshell is rarely owned by the construction companies in Malaysia, but it is mainly used to transfer the removed soil from the bottom level of the excavation area to the lorries in a TDC project. Therefore, it is necessary to import specific machinery from other countries or rent from other companies and the construction cost for hiring plants is increased.

Correspondingly, difficulties on activities planning and project tendering have a lower possibility compared to other issues. In the respondents' opinion, 
design and build contract is not suitable for a TDC project because of the high requirement of details needed during the tendering stage. Contractors need to include cost and time for machinery idling and temporary platform for the machinery's operation in their quotation.
Moreover, Malaysia is prone to monsoon rains over the years and causes the uncertainty of the groundwater level. Hence, it is important to monitor the groundwater level during the excavation work and install required dewatering system to discharge the water.

Table II Percentage of Respondents for each Possible Problems

\begin{tabular}{|c|c|c|c|c|c|c|c|c|}
\hline \multirow[t]{2}{*}{ Possible Problems } & \multicolumn{3}{|c|}{ Number of Respondent } & \multicolumn{3}{|c|}{ Percentage (\%) } & \multirow[t]{2}{*}{ R.I.I } & \multirow[t]{2}{*}{ Ranking } \\
\hline & $\mathbf{L P}$ & PO & MP & $\mathbf{L P}$ & PO & MP & & \\
\hline Require Professional Contractor & 4 & 44 & 54 & 3.92 & 43.14 & 52.94 & 0.830 & 1 \\
\hline Require Specific Machinery & 9 & 44 & 49 & 8.82 & 43.14 & 48.04 & 0.797 & 2 \\
\hline Higher Construction Cost & 11 & 48 & 43 & 10.78 & 47.06 & 42.16 & 0.771 & 3 \\
\hline Require Complicated Design & 12 & 51 & 39 & 11.76 & 50.00 & 38.24 & 0.755 & 4 \\
\hline Difficult to Plan and Manage the Activities & 18 & 60 & 24 & 17.65 & 58.82 & 23.53 & 0.686 & 5 \\
\hline Difficult for Tendering & 34 & 56 & 12 & 33.33 & 54.90 & 11.76 & 0.595 & 6 \\
\hline Longer Construction Duration & 58 & 35 & 9 & 56.86 & 34.31 & 8.82 & 0.507 & 7 \\
\hline
\end{tabular}

\section{F. Possible Suitable Location for TDC Method}

The responses in Fig. 3 shows that majority of the industry players in Malaysia agree that construction in the urban area surrounded by buildings with deep and raft foundation or with a congested traffic condition is more suitable for TDC method. It satisfied with Huang et al. [18] that open excavation using conventional bottom-up construction method generates a significant loss of soil stability to the surrounding buildings especially those with deep foundation. Hence, the casted ground floor in the TDC project is able to act as a permanent lateral support to the surrounding buildings.

On the other hand, metro stations or other underground structures constructed in a congested urban area are more often to be excavated using the TDC method because the supporting system is stiffer than the bottom-up method. Soil removal during excavation will cause the rebound of the basal. However, weight of the cast sub-structure during an earlier stage in the TDC project can suppress and minimise the level of rebound.

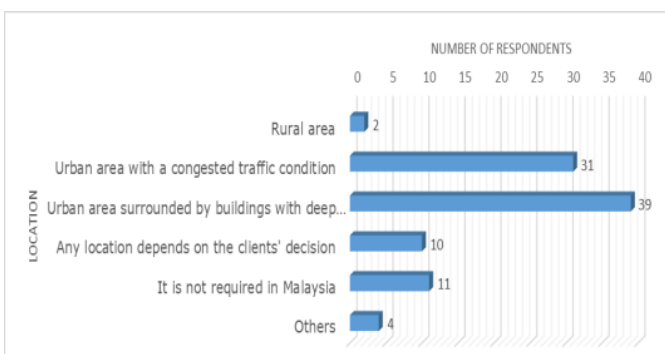

Figure 3. Summary of Suitable Location for TDC Method

\section{G. Effectiveness of the TDC Method}

This section focuses on the discussion about the effectiveness of the TDC in Malaysia. Several items have been concluded from the other researches regarding the advantages of adopting TDC method and to verify the effectiveness of the method in Malaysia.

Fig. 4 shows the result of the respondents who agree the listed items of advantages of this method in Malaysia. It can be summarised that most of the respondents
(93.1\%) pointed out that it is useful for the construction of the structure with deep basement where the ground influence zone is particularly noticeable during excavation.

As illustrated in Fig. 5, there is lesser than $40 \%$ of respondents from each category agree that TDC method can effectively reduce the cost of the project in Malaysia. It can be explained by the unfamiliarity with this method and consideration taken during the tendering stage such as machinery idling, work mistake as well as the requirement of specific machinery.

Structural consultancies are surprisingly pessimistic about the benefit of the TDC method especially reduction of the temporary structure compared to the other categories. From the view of the structural consultancies, a temporary support system is required when the permanent concrete structure like floor slab has not achieved the desired strength to support the diaphragm wall from soil movement.

All respondents from the geotechnical consultancies claimed that TDC method is useful for the deep basement sub-structure, proves Tan and Wang [19] on the Shanghai World Finance Center building which is constructed on the soft clay with $17.85 \mathrm{~m}$ deep sub-structure using this TDC method and no significant ground settlement occurs.

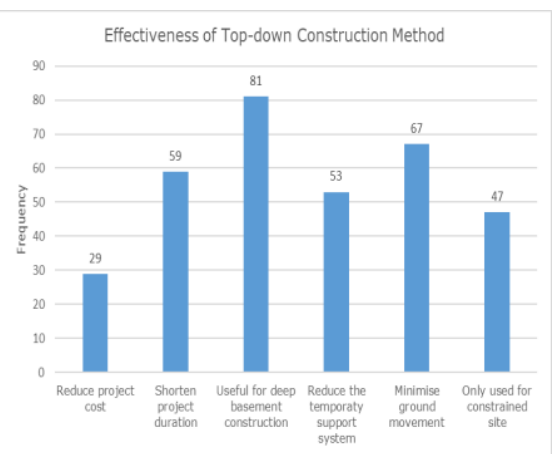

Figure 4. Summary of Respondents to each Effectiveness

Published By: Blue Eyes Intelligence Engineering \& Sciences Publication 


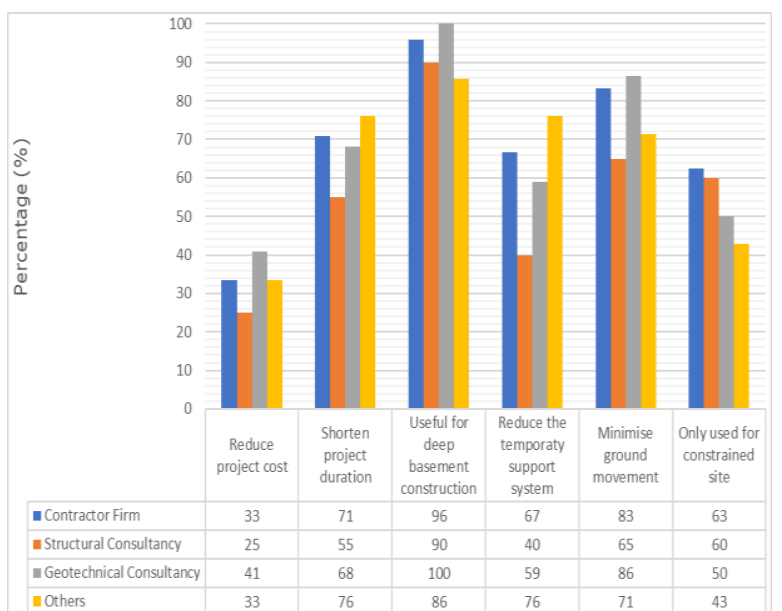

Figure 5. Summary of Respondents for each Effectiveness according to Category

\section{CASE STUDY}

The project site is located in the Kuala Lumpur City Centre (KLCC). It is divided into two zones which are Package One and Package Two. Fully TDC method is adopted by Package Two while a combination of the topdown and bottom-up method is used in the Package One.

The studied project is the first project constructed using TDC technique by the company. From the interview session, one of the reasons for choosing this method in this project is due to the site limitation. The project site is surrounded by few existing high-rise buildings with deep basement carpark and underground tunnel. Conventional bottom-up construction method cannot be applied in this project because of the huge soil pressure from the neighbouring buildings whereby the lateral force is unable to be resisted by the temporary support system. Even diaphragm wall is used in this project to sustain the soil pressure, the thickness of the wall is up to $1000 \mathrm{~mm}$ with the necessity of extra reinforcement in the permanent slab for the lateral force resistance.

Due to the existing underground services and other future development plan, ground anchors are not allowed to install in this project for most of the peripheral area. Hence, top-down with the diaphragm wall construction is the only feasible method in this project. The project manager of Package Two explained that there are other supporting systems such as secant pile wall or contiguous bored pile wall (CBP) can be used in the TDC project. However, the diaphragm wall has the most ideal performance in term of rigidity and watertight ability.

\section{A. Implementation for Project Effectiveness Improvement}

There are some specific methods used in the project to improve the project effectiveness on safety, quality and environment aspects.

\section{(i) Introduction of "Dummy"}

Plunge-in column is installed in the desired location before the excavation in the TDC project and it acts as a permanent support to the buildings. However, it is found to have potential wastage and logistic problem during the installation stage. Additional parts above the ground level limit the movement of the machinery and double handling job is needed to weld and cut the additional part. The unnecessary hot work and wastage lead to the potential safety and environmental problem.

A removable "Dummy" as shown in Fig. 6(a) is introduced to replace the additional length of the plungein column, it connects with the plunge in column using the bolting system. Hence, it is used to notably reduce the cutting work and can be operated by the normal workers. Due to the removability, the protrusion part of the plunge in column can be prevented and more space is allowed for machinery movement as well as easier for storage on site.

\section{On-site Dewatering System}

Excavation's productivity highly depends on the water table level. The excavation work cannot proceed if the soil is muddy after raining or when the water table is high. Due to this problem, a lot of vertical holes with perforated casing (to avoid ground collapse) are installed during the piling stage as illustrated in Fig. 6(b) for dewatering. It uses to collect the water from the excess groundwater and the raining water then pump out to the desired storage so that the excavation work can carry on.

\section{(iii) Use of "Plastech" Formwork}

An alternative lightweight plasform panel called "Plastech" is used to replace the typical plywood and timber formwork in this project. It is more reusable compare to conventional wooden formwork and easier for removal. It minimises the time for erecting formwork after the excavation is completed and shorten the project duration.
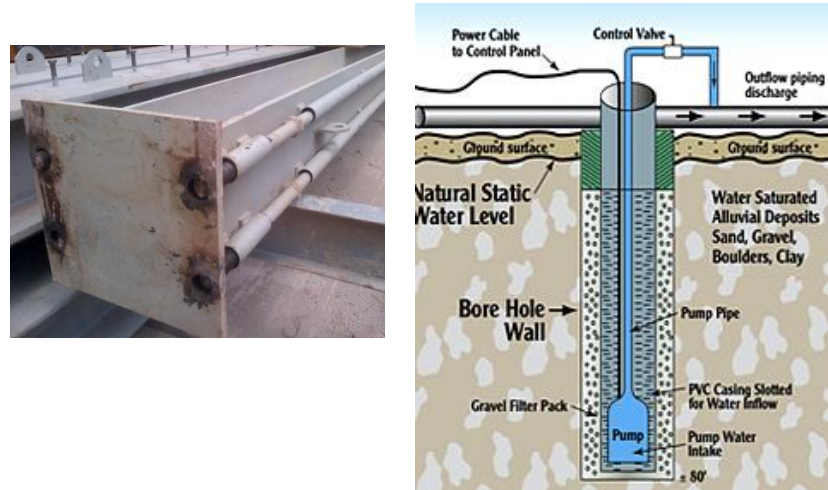

Figure 6. (a) "Dummy" of Plunge-in Column; (b) Schematic Diagram of Dewatering Well [20]

\section{PROPOSED IMPROVEMENT METHOD}

\section{A. Questionnaire Result}

Few approaches stated in the past researches are used to collect the responses from the local industry players to study the feasible solutions in Malaysia. From Table III, it can be concluded good planning on the excavation activity and the construction of structural members can improve the effectiveness of this method during the preliminary stage. Planning should be done beforehand to minimise the opportunity of activity crashing.

The result also showed that a better work supervision can achieve the improvement. Project executive in the 
project studied suggested that communication is highly demanded to ensure that each party can have the latest work progression update.

Only $40 \%$ of the respondents agreed that prefabricated structure is useful to improve the project effectiveness.
From the opinion of the technical manager, prefabricated structural members are only applicable for certain locations which have no obstruction for the structural members to be delivered.

Table III Summary for Degree of Importance of each Improvement Method

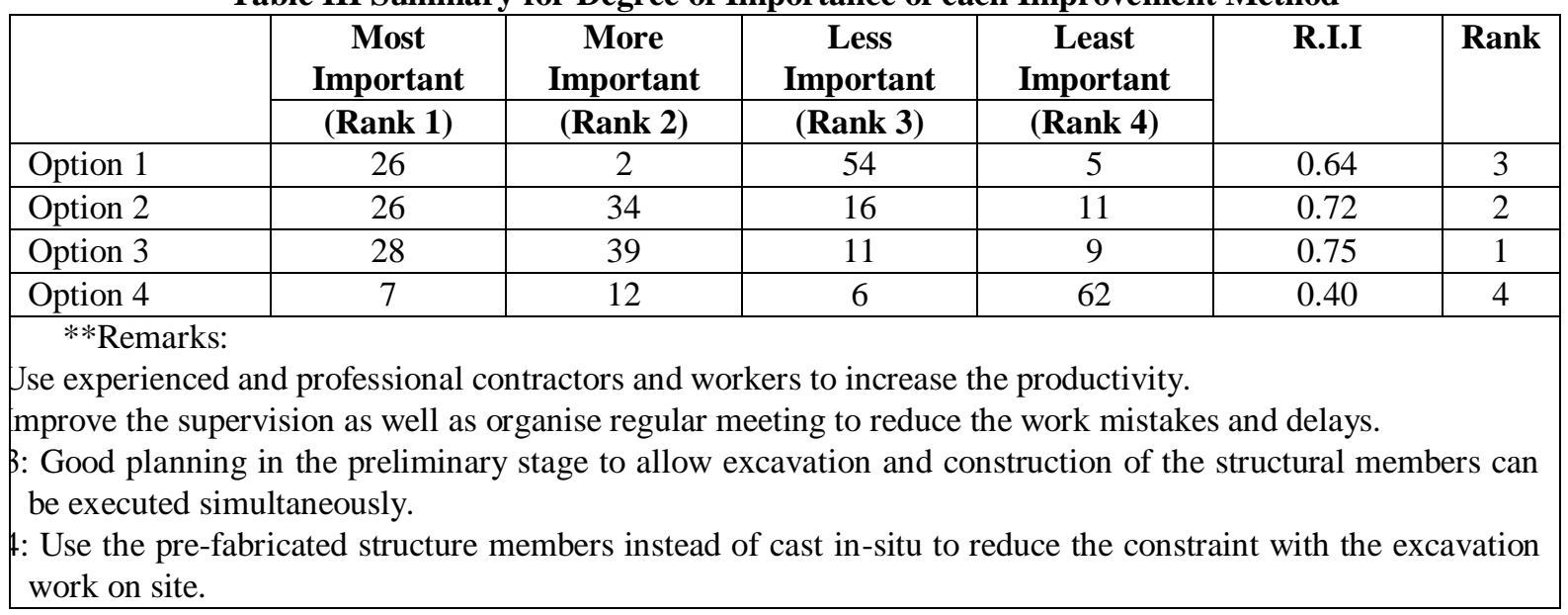

\section{B. Semi Top-down Construction Method}

Semi top-down method is a combination of typical bottom-up excavation and the TDC method. The construction starts with the excavation until a certain level of the sub-structure using bottom-up method followed by the casting of the floor slab, after that, the soil excavation continues under the floor and the construction of the permanent structural members can be executed using TBC method [18].

This method can significantly shorten the excavation time in comparison to fully TDC method. Meanwhile, the support system to the ground movement is stronger because of the earlier completion of the floor slab prior to the excavation of the lower part.

\section{Channel-type Excavation}

Channel-type excavation is proposed by Li et al. [21] to achieve a continuous construction and excavation under a confined space. Fig. 7 shows an operation channel is excavated from the outlet to the farthest end of the excavation area, the remaining soil on both sides of the channel acts as a support to resist the movement of the diaphragm wall. After that, the completely excavation starts from the farthest end of the area and proceeding backward. Concurrently, the construction of the permanent structural members can be started from the farthest end without blocking the excavation path.

Access of the machinery and the resistance ability to the wall displacement are the key issues to determine the channel width. From the case study done by $\mathrm{Li}$ on the metro station in China, there are a significant $39.1 \%$ decrease in project time and $14.3 \%$ reduction in the project cost by adopting channel-type excavation in comparison to conventional segmental excavation [21].

\section{Use of Concrete Admixture}

One of the problems causing the low productivity of the TDC method in Malaysia is the concrete curing waiting time of 28 days. Hence, it is possible to use the concrete admixtures to modify the properties of the concrete and accelerate the speed of gaining desired strength.

Cement accelerator is suggested to add into the concrete to shorten the setting time and increase the hardening rate as well as strength development of concrete. The principle of the accelerator is to increase the hydration rate of the hydraulic cement and conventional chemical materials used in the construction industry nowadays are calcium nitrate ( $\mathrm{Ca}(\mathrm{NO} 3) 2)$ and sodium nitrate ( $\mathrm{NaNO} 3)$.

Machinery is able to work on the concrete at an earlier stage due to the more rapid achievement of the designed strength. However, it is necessary to carry out benefitcost analysis to justify the cost spent on the accelerators is valuable for the growth of project benefit and related study on the effects of admixtures like corrosion on steel reinforcement is required before adopting this technique.

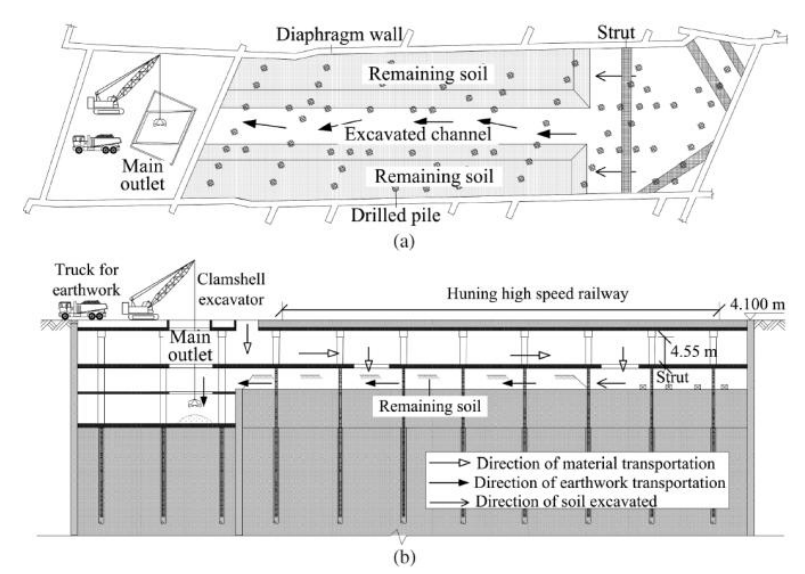

Fig 7. Schematic diagram of channel-type excavation: (a) plan view (b) profile view [21] 


\section{CONCLUSION}

Conclusively, it is revealed that the awareness of TDC method in Malaysia is considerably high. However, only $44.12 \%$ of the respondents involved in the related project before. $60 \%$ of the respondents agreed that TDC is a more feasible method than the bottom-up construction and generate lesser safety problem. Urban area surrounded by the buildings with deep foundation or with a congested traffic condition are reported to be the most suitable locations for adopting TDC method in Malaysia because it produces lesser ground movement and efficient for the deep basement construction. The most significant issues when implementing this method in Malaysia are the requirement of professional contractors and specific machinery which impose higher construction cost to a project. Limitation headroom which causes the confined working environment for the machinery and machinery idling had been identified as the most common site problems for the TDC project.

The followings are proposed improvement methods that can be used as a guide and hence to improve the effectiveness of the TDC method in Malaysia.

(i) Proper planning in the preliminary stage is necessary to allow excavation and construction of the structural members can be executed simultaneously.

(ii) Dummy is introduced in the project studied to reduce the wastage of the plunge-in column and the logistic problem on ground level. Dewatering wells are installed on site to control the groundwater table level and pump out the exceeding water on site due to downward excavation. Alternative "Plastech" formwork is used to replace conventional formwork in the project studied because it is reusable and has a faster erection time.

(iv) Other methods such as semi TDC method, channel-type excavation and use of concrete admixture to shorten the hardening time of the concrete components are proposed by the researcher based on the other research conducted in other countries.

\section{REFERENCES}

1. Department of Statistics Malaysia. 2019. Retrieved 14 May 2019<https://www.dosm.gov.my/v1/index.php?r=col umn/cthemeByCat\&cat=77\&bul_id=Z2V5Q1ZCQjN 0WTlqaUkrai9rRjlCZz09\&menu_id=OEY5SWtFSV VFVUpmUXEyaHppMVhEdz09>

2. Finno, R. J., Atmatzidis, D. K. and Perkins, S. B. 1989. Observed performance of a deep excavation in clay. Journal of Geotechnical Engineering. 115(8): 1045-1064.

3. Tan, Y. and Wang, D. 2013. Characteristic of a large-scale deep foundation pit excavated by the central-island technique in Shanghai soft clay. I: Bottom-up construction of the central cylindrical shaft. Journal of Geotechnical and Geoenvironmental Engineering. 139(11): 1875-1893.

4. Basarkar, S. S., Kumar, M., Mohapatro, B. G. and Mutgi, P. R. 2013. Emerging trend in deep basement construction: Top-down technique. IOSR Journal of Mechanical and Civil Engineering. 5: 1-11.

5. Zinn, W. V. 1968. Economic design of deep basements. Civil Engineering and Public Works Revolution. 68: 275280.
6. Paek, J. H. and Ockz, J. H. 1996. Innovative building construction technique: Modified up-down method. Journal of Construction Engineering and Management, 122(2): 141-146.

7. Yurkevich, P. B. 2013. Development top-down method of underground construction or hi-tech in Russian. World Underground Space. 5: 11-27.

8. Hwang, R. N. and Moh, Z. C., 2007. Performance of floor slabs in excavations using top-down method of construction and correction of inclinometer readings. Journal of GeoEngineering. 2(3): 111-121.

9. Marchant, S., Wren, G. and Lamb, R. 1994. Top-down construction and its implications. Proceedings of the Institution of Civil Engineers - Geotechnical Engineering, 107(2), pp. 123-124.

10. De Wit, A. 1988. Measurement of project success. Project Management Journal. 6(3): 164-170.

11. Endut, I. R., Akintoye, A. and Kelly, J., 2003. Cost and time overruns of projects in Malaysia. Journal of Construction Research. 4(2): 243-252.

12. Othman, A. A., Torrance, J. V. and Hamid, M. A., 2006. Factors influencing the construction time of civil engineering projects in Malaysia. Civil Engineering Projects in Malaysia. 13(5): 481-501.

13. Wright, J. N. 1997. Time and budget: the twin imperatives of a project sponsor. International Journal of Project Management. 15(3): 181-186.

14. Chan, D. W. and Kumaraswamy, M. M., 1997. A comparative study of causes of time overruns in Hong Kong construction projects. International Journal of Project Management. 15(1): 55-63.

15. Chelsea, G., 2015. Using and Interpreting Cronbach's Alpha. [Online]. RetrievedL 20 April 2017. $<\mathrm{http}$ ://data.library.virginia.edu/using-andinterpreting-cronbachs-alpha/>

16. Mohsen T. and Reg. D. 2011. Making Sense of Cronbach's Alpha. International Journal of Medical Education. 2: 5355.

17. Choo, W. K. 2010. The construction guideline of using top-down method.

18. Huang, R., Kang, Z., Tan, Y. and Bin, W. 2016. Covered semi top-down excavation of subway station surrounded by closely spaced buildings in downtown Shanghai: Building response. Journal of Performance of Construction Facilities. 30(6): 1-1

19. Tan, Y. and Wang, D. 2013. Characteristic of a large-scale deep foundation pit excavated by the central-island technique in Shanghai soft clay. II: Top-down construction of the peripheral rectangular pit. Journal of Geotechnical and Geoenvironmental Engineering. 139(11): 1894-1910.

20. Gambit Engineering Consultancies Pvt Ltd. 2015 Dewatering. Retrieved $11 \quad$ April 2017 <http://www.gambitgroups.com/?page_id=770>

21. Li, M. G., Chen, J. J., Xu, A. J. and Xia, X. H. 2014. Case study of innovative top-down construction method with channel-type excavation. Journal of Construction Engineering Management, 140(5): 1-1. 